\title{
A casa dos avós: 0 papel do contacto com os avós nas perceções idadistas de crianças do ensino básico
}

\author{
Mariana Ribeiro ${ }^{1}$ Teresa Reis $^{1}$, Sibila Marques ${ }^{2}$, Joana Mendonça ${ }^{2}$, Ricardo Borges \\ Rodrigues $^{2}$ \& Filomena Gerardo ${ }^{1,2}$ \\ ${ }^{1}$ Departamento de Ação Social e Saúde da Santa Casa da Misericórdia de Lisboa \\ 2 Iscte - Instituto Universitário de Lisboa, CIS-IUL, Lisboa, Portugal
}

\begin{abstract}
Resumo: Existem evidências de que crianças a partir dos seis anos de idade já partilham a conceção paternalista das pessoas mais velhas como "simpáticas, mas incompetentes". De forma inovadora, o presente trabalho visa estudar este tema no contexto português procurando explorar o papel da frequência e qualidade do contacto com os avós como uma via para a diminuição destas representações negativas. Para tal, 145 crianças do ensino básico $(M=12.14 ; S D=0.81)$ responderam a um inquérito com o intuito de explorar a relação entre estas variáveis. De acordo com as hipóteses, os resultados revelaram um elevado grau de contacto com os avós e um efeito significativo da frequência e da qualidade do contacto na diminuição do idadismo face às pessoas idosas. Estes resultados são discutidos à luz das suas implicações para a teoria e intervenção neste domínio de relevância crucial no contexto demográfico atual.
\end{abstract}

\section{Palavras-chave: Preconceito; idadismo; crianças; contacto com os avós.}

Grandfather's house: The role of contact with grandfathers on ageism perceptions of elementary school children: There is evidence that children from the age of six already share the paternalistic conception of older people as "doddering but dear". In an innovative way, this research aims to study this theme in the Portuguese context, seeking to explore the role of frequency and quality of contact with grandparents as a way of diminishing these negative representations. To that end, 145 elementary school children $(M=12.14 ; S D=0.81)$ responded to an inquiry to explore the relationship between these variables. According to the hypothesis, the results revealed a high degree of contact with grandparents and a significant effect of the frequency and the quality of the contact in the decrease of ageism towards older people. These results are discussed in light of their implications for theory and intervention in this area of crucial relevance in today's demographic context.

Keywords: Prejudice; ageism; children; contact with grandparents.

\section{O Idadismo nas crianças}

A literatura sobre o desenvolvimento das relações intergrupais na infância é vasta e tem focado contextos intergrupais modelados a partir das categorias raciais, étnicas, de género e nacionalidade (para uma revisão ver Killen \& Rutland, 2011; Monteiro, 2017). Nesta linha, e em Portugal, vários estudos têm mostrado que as atitudes e os comportamentos de crianças face aos seus pares em contexto escolar são fortemente marcados por processos de auto e hetero categorização e identificação em torno de categorias raciais (Monteiro, 2002). Especificamente, as crianças Brancas tendem a avaliar de forma menos favorável as crianças Negras (Rodrigues et al., 2012), sendo igualmente notório que a expressão destas avaliações se modifica com a idade e de acordo com o contexto, reproduzindo não só as atitudes maioritárias dos adultos, mas igualmente as posições normativas destes relativamente às formas adequadas de expressão do preconceito racial (França \& Monteiro, 2013; Monteiro et al., 2009).

Embora a categoria idade constitua uma dimensão central para as crianças e que organiza a sua construção da realidade social desde muito cedo (Mendonça et al., 2018), o estudo do seu impacto nas relações intergrupais na infância tem sido mais esporádico e disperso. No entanto, a sua análise constitui uma oportunidade de verificar se o desenvolvimento das atitudes idadistas, e concretamente em crianças face a adultos séniores, coincide com aquele registado noutros contextos intergrupais.

Vários autores têm-se dedicado ao estudo da segregação etária como um dos fatores promotores da ausência de relacionamento entre as diferentes gerações (Hagestad \& Uhlenberg, 2005). Entende-se por segregação etária a modelação do contacto entre grupos etários no quadro da construção social de um ciclo 1 Morada para correspondência: Sibila Marques, Iscte-Instituto Universitário de Lisboa, Av. das Forças Armadas, 1649-026 Lisboa E-mail:
sibila.marques@iscte-iul.pt 
de vida que se divide em três fases principais: a primeira fase relacionada com a educação, a segunda com a construção da família e o desenvolvimento de uma atividade laboral, e a terceira e última relacionada com o processo de envelhecimento e a reforma profissional. Este ciclo cria uma descontinuidade entre as gerações promovendo o seu afastamento e, por vezes, a ausência de interação. É nesta última fase do ciclo, na reforma, que tem lugar a exclusão social das pessoas mais velhas, associada a situações de discriminação face à idade (Hagestad \& Uhlenberg, 2005) e à prevalência de atitudes negativas face à idade ainda, largamente, aceites nas sociedades modernas (Nelson, 2004).

O idadismo, refere-se, assim, a atitudes e práticas negativas generalizadas em relação aos indivíduos tendo em conta a idade (Marques, 2011). As atitudes idadistas podem ocorrer tanto em relação a pessoas mais jovens como a pessoas idosas (Greenberg et al., 2004), embora neste trabalho foquemos a nossa atenção no idadismo em relação às pessoas mais velhas.

Em termos gerais, as atitudes idadistas são compostas por três elementos principais (e.g., Hagestad \& Uhlenberg, 2005; Marques, 2011; Steele et al., 2004;). 0 primeiro caracterizado por uma componente cognitiva, correspondente às crenças criadas acerca de uma pessoa ou grupo (estereótipos); o segundo referente a uma componente afetiva, que inclui a manifestação de preconceitos ou sentimentos negativos dirigidos a uma pessoa ou grupo (preconceito), e o terceiro referente à dimensão comportamental, da qual fazem parte os comportamentos discriminatórios (discriminação) (Brown \& Bigler, 2004).

A categorização social com base na idade desenvolve-se entre os 2 e os 7 anos de idade (Johnson \& Medinnus, 1974) e possibilita os processos de socialização que envolvem a transmissão de perceções e atitudes sociais idadistas que contribuem para o desenvolvimento das atitudes idadistas das crianças face a pessoas idosas (Greenberg et al., 2004). Várias pesquisas têm chamado a atenção para este preconceito dos mais novos face aos mais velhos, referindo que crianças em idade pré-escolar já avaliam as pessoas idosas de forma mais negativa, demostrando preferência pela participação de adultos mais novos em atividades conjuntas (Montepare et al., 2005).

Desta forma, crianças com idades entre os 3 e os 7 anos já revelam atitudes negativas sobre o processo de envelhecimento (Seefeldt et al., 1977), e que tendem a rigidificar-se ao longo do desenvolvimento infantil (Crawford \& Bhattacharya, 2014). Por exemplo, um estudo recente realizado no contexto português mostrou que, desde os 6 anos de idade, as crianças partilham o estereótipo ambivalente de que as pessoas idosas são "mais simpáticas do que competentes" (Vauclair et al., 2017). Este estereótipo tem sido identificado de forma consistente em amostras adultas e tem consequências negativas na avaliação das pessoas idosas que são normalmente vítimas de paternalismo e de pena (Cuddy et al., 2005). Esta forma de paternalismo pode ser conceptualizada como uma forma indireta de preconceito tal como sucede noutros tipos de expressões do preconceito na infância (França \& Monteiro, 2013; Monteiro et al., 2009).

Um caminho para a desconstrução destes estereótipos pode passar pela aproximação das gerações, incentivando os comportamentos pró-sociais através do fortalecimento das relações entre ambas (Newman et al., 1997).

É nesta perspetiva que surge o conceito de intergeracionalidade, referindo-se à promoção do contacto entre diferentes gerações através de aprendizagens e objetivos comuns (França et al., 2010) com atividades promotoras desse contacto positivo (Jarrott, 2011). A participação nestas atividades contribui para que as gerações mais novas compreendam de melhor forma todo o processo de envelhecimento, incentivando assim a diminuição do estereótipo idadista e o desenvolvimento de um sentimento de igualdade, estima e apreço pelos mais velhos (Cuddy et al., 2005).

De forma inovadora, este trabalho pretende contibuir para a investigação neste domínio, procurando explorar o modo como as crianças portuguesas percebem as pessoas idosas. Em particular, estamos interessados em investigar o papel que o contacto com os avós pode ter nestas perceções.

\section{O contacto com os avós como forma de reduzir o idadismo}

A promoção do contacto entre gerações sub-entende dois tipos de interação intergeracional: o primeiro, que diz respeito à relação parental estabelecida entre avós e netos, muito relevante para a perceção do processo de envelhecimento destes (Drew \& Silverstein, 2007; Dunifon \& Bajaracharya, 2012), e o segundo respeitante às relações geracionais que se estabelecem fora do contexto familiar (Kaplan \& Larkin, 2004).

Relativamente à relação entre avós e netos, e à sua importância para o desenvolvimento saudável infantil, Caspi (1984) afirma que a discriminação face à idade pode ser combatida com o aumento do contacto positivo entre ambas as gerações como ocorre, por exemplo, na relação avós-netos. Tal acontece, pois este tipo de relação envolve dimensões pessoais e intimistas que são muito importantes na mudança das atitudes idadistas (Brown \& Hewstone, 2005).

Num estudo realizado por Harwood e colegas (2004), com estudantes universitários, são explicadas as diferenças entre as atitudes positivas relativamente a pessoas idosas concretas e as atitudes face a 
pessoas idosas em geral. Através desta abordagem, foi possível verificar que as atitudes positivas para com os avós influenciam o modo como as "pessoas idosas" são percebidas de um modo geral. Desta forma, os fatores interpessoais contribuíram para o desenvolvimento de experiências afetivas íntimas consideradas como importantes na mudança de atitude (Pettigrew \& Tropp, 1997).

Estes resultados estão de acordo com as previsões originais de Allport (1954) quando destaca a relevância da qualidade do contacto como fator crucial para a mudança das atitudes inter-grupais. Desta forma, Allport (1954) defendeu que o contacto deve ser significativo de forma a agir eficazmente na redução do preconceito e a aumentar as atitudes positivas relativamente ao exogrupo. Em suma, este contacto deve ser frequente e, ao mesmo tempo, positivo e de qualidade (para uma revisão ver Monteiro, 2017).

Num outro estudo realizado por Kite e Johnson (1988), novamente com estudantes universitários, foram estudadas as relações entre avós e netos, com ênfase na influência deste contacto relativamente ao preconceito para com pessoas idosas. Estes autores referem que o contacto com os avós influencia as atitudes face aos adultos mais velhos, ou seja, quanto maior o incentivo das relações entre avós e netos, mais positivas tendem a ser as atitudes face às pessoas idosas no geral e, por consequência, face ao próprio processo de envelhecimento (Soliz \& Harwood, 2003). Assim, quando a idade é um fator evidente, o contacto existente com os avós irá proporcionar atitudes mais positivas dos netos para com outras pessoas mais velhas (Hewstone \& Brown, 1986).

Dados avançados por Silverstein e Parrott (1997) evidenciam, ainda, que aqueles que têm contacto assíduo com os avós durante a infância desenvolvem opiniões mais positivas e duradouras sobre o processo de envelhecimento, reduzindo a ansiedade e o preconceito em relação a esta etapa do desenvolvimento humano. Desta forma, os avós são vistos como figuras de relevância entre a família (Veleda et al., 2006) sendo esta relação, entre avós e netos, estimulada pelos pais (Dias \& Silva, 1999).

Para além dos fatores que parecem marcar o tipo de relação significativa entre avós e netos, o sexo dos avós parece constituir uma variável relevante. Vários autores têm demostrado que as avós tendem a construir um relacionamento mais próximo com os seus netos do que os avôs (Drew \& Silverstein, 2007; Dunifon \& Bajaracharya, 2012). Neste sentido, várias pesquisas têm destacado o papel das avós quando têm os netos ao seu cuidado, designadamente o seu contributo para a saúde e bem-estar dos netos, proporcionando-lhes condições favoráveis de crescimento (Pires, 2010).

Esta proximidade entre avó e netos, bem como o tempo despendido no cultivo desta relação de partilha promove maiores níveis de comunicação e afetividade entre eles (Dutra, 2008), sendo esta relação descrita pelos netos como de amor incondicional, respeito, amizade e confidência (Kemp, 2005). Neste sentido, uma das características mais importantes no relacionamento intergeracional é o caráter recíproco e complementar que esta convivência oferece para ambas as gerações (Drew \& Silverstein, 2007).

Ainda num estudo mais recente, mas realizado com estudantes universitários, Soliz e Harwood (2006) exploram o papel que variáveis específicas na relação com os avós têm no idadismo em relação às pessoas idosas de um modo geral. Neste estudo os autores destacam a importância de duas variáveis que parecem desempenhar um papel fundamental: a perceção dos avós como fazendo parte da identidade familiar e a saliência da idade. A família pode ser considerada o endogrupo com mais relevância para o self (Soliz \& Harwood, 2006) e espera-se que quanto mais o jovem percebe o avô/avó como fazendo parte desta identidade familiar, mais positivas serão as avaliações deste/desta, o que poderá ser generalizado às restantes pessoas idosas. Este efeito deve ser moderado pelo grau em que a idade do avô/avó é saliente, isto é, quanto mais os jovens considerarem o avô/avó como parte da categoria das pessoas idosas (e.g., como uma pessoa idosa típica), maior o efeito positivo da identidade familiar na perceção das outras pessoas idosas.

Os estudos já referidos mostram o quão significativas podem ser as relações com os avós na mudança das atitudes em relação às pessoas idosas de um modo geral. No entanto, são muito poucos os estudos que exploram o papel destas variáveis em crianças mais novas. Uma exceção é o estudo recente de Flamion e colaboradores (2017) publicado na revista Child Development e realizado com crianças e adolescentes belgas com idades entre os 7 e os 16 anos. Este estudo apresenta, pela primeira vez, resultados que demonstram os efeitos do contacto com os avós na diminuição das perceções idadistas face às outras pessoas idosas. Com particular relevância, este estudo revela que são as dimensões da qualidade do contacto aquelas que têm mais peso na redução do idadismo. No entanto, importa saber se estes resultados são extensíveis a outros contextos culturais.

Por exemplo, que seja do nosso conhecimento não existem estudos realizados com crianças portuguesas sobre o papel do contacto com os avós no idadismo face às pessoas idosas. É ainda relevante que o presente estudo pretenda contribuir para o estudo das dinâmicas idadistas num contexto de envelhecimento demográfico que ocorre atualmente na sociedade portuguesa, com expectável progressão no futuro (INE, 2002). 
Portugal apresenta mutações demográficas de ampla escala e com importantes repercussões sociais, económicas e culturais. A evolução demográfica em Portugal, no passado recente, caracterizou-se por um gradual aumento do peso dos grupos etários séniores e uma redução do peso da população jovem. Segundo o INE (2002), a população residente em Portugal tende a diminuir até 2060, em todas as projeções. A população diminui de 10,5 milhões de pessoas, em 2012, para 8,6 milhões de pessoas, em 2060. Para além do declínio populacional, esperam-se, ainda, alterações da estrutura etária da população, resultando num continuado e forte envelhecimento demográfico. Assim, prevê-se que, entre 2012 e 2060, o índice de envelhecimento aumente de 131 para 307 idosos por cada 100 jovens.

O estudo europeu "A prestação de cuidados pelos avós na Europa" (Glaser et al., 2013) realizou uma análise comparativa das políticas familiares e da sua influência no papel dos avós enquanto prestadores de cuidados infantis em vários países Europeus. Portugal é considerado um dos países em que os avós mais cuidam dos netos, e o país com o maior número de mães com filhos até aos seis anos a trabalhar a tempo inteiro. Segundo o estudo, mais de $40 \%$ dos avós dos países europeus analisados prestam cuidados aos netos sem a presença dos pais, sendo que os países do sul da Europa -Portugal, Espanha, Itália e Roménia - são os que apresentam uma maior percentagem (63\%, aproximadamente) de avós a cuidar dos netos a tempo inteiro. A justificação para a maior dependência dos cuidados prestados pelos avós é atribuída à pouca oferta de estruturas formais de acolhimento de crianças a preços acessíveis. Portugal, por sua vez, tem também assistido a um aumento de agregados familiares de avós com três gerações (Glaser et al., 2013). Neste sentido, oferece um contexto particularmente importante para o estudo deste tipo de relações intergeracionais.

\section{OBJETIVOS DO PRESENTE ESTUDO}

0 presente estudo pretende explorar, pela primeira vez, de que modo a frequência e a qualidade do contacto entre os avós e netos pode influenciar o idadismo em relação às pessoas idosas, no contexto português. De um modo inovador na literatura neste domínio pretende-se explorar, ainda, o papel que a variável identidade familiar e saliência da idade (i.e., tipicalidade do avô/avó enquanto pessoa idosa) desempenham neste processo. De acordo com a literatura neste domínio espera-se que:

H1: Maior frequência no contacto com os avós esteja relacionado com estereótipos e emoções mais positivos em relação às pessoas idosas.

H2: Maior qualidade percebida no contacto com os avós esteja relacionada com estereótipos e emoções mais positivos em relação às pessoas idosas.

H3: Quanto mais as crianças perceberem o avô/avó como parte da identidade familiar, mais positivos serão os estereótipos e as emoções em relação às pessoas idosas, particularmente quando o avô/avó é percebido como mais típico da categoria das pessoas idosas.

\section{MÉTODO}

\section{Caracterização da Amostra}

Participaram neste estudo 145 jovens estudantes. A amostra foi constituída por 60 participantes do sexo feminino e 85 participantes do sexo masculino. A idade dos participantes varia entre os 11 e os 13 anos, sendo a média de idades de, aproximadamente 12.14 anos $(M=12.14 ; D P=0.81)$. Estes participantes encontravam-se o 6.ำ 7. e 8.ํaa ano numa Escola Básica, situada na Região do Algarve. A maioria é de nacionalidade portuguesa (98.6\%), em comparação com outras nacionalidades $(1.4 \%)$.

Quanto à dimensão, partilha de habitação, 75\% dos participantes habitam com o pai e a mãe, 14,6\% um tempo com o pai e um tempo com a mãe e $10.4 \%$ só com o pai ou só com a mãe. Em relação à partilha de habitação com os avós, 88.3\% dos participantes não habita com os avós em detrimento de $11.7 \%$ dos participantes que partilha habitação com os avós.

Numa maneira geral os participantes têm mais contacto com a avó materna (44.1\%) e o avô materno (15.9\%), em relação à avó paterna (22.8\%) e o avô paterno (9.7\%). Existem ainda alguns casos em que os participantes estabelecem contacto em simultâneo com a avó e avô materno e paterno (1.4\%) e com todos os avós $(2.1 \%)$.

É de salientar que apenas 3.4\% dos participantes desenvolvem outros contactos com pessoas idosas, fora do contexto familiar, existindo um ou outro caso em que os participantes partilham uma relação com os seus bisavós $(0.6 \%)$.

\section{Instrumentos}

Para a realização da avaliação foi entregue aos pais o consentimento informado, onde lhes era apresentado uma breve explicação do projeto, bem como era solicitada a autorização para a sua participação e dos respetivos educandos no mesmo. 
Estereótipos de envelhecimento: perceção de competência e afectuosidade. No presente estudo, tivemos como base o questionário aplicado no programa imAGES (Marques et al., 2015), onde foi pedido aos participantes que pensassem nas pessoas idosas com 65 anos ou mais, e em que medida achavam que os idosos são: confiantes, capazes, habilidosos, amigáveis, de confiança e sinceros. Ainda neste contexto, foram criadas duas variáveis a partir dos conceitos que caracterizam as pessoas idosas, o Estereótipo de Competência que avalia a confiança, capacidade e habilidade das pessoas idosas e o Estereótipo de Afetuosidade que avalia a amizade, o facto destas serem de confiança e a sinceridade. Estas escalas baseiam-se nos estudos de Fiske e colaboradores (2002). Os itens de resposta foram medidos a partir de uma escala de Likert de 7 pontos (1- Discordo completamente a 7- Concordo completamente).

A análise de consistência interna confirmou que o Estereótipo de Competência alcançou uma confiabilidade excelente $(\alpha=.93)$, assim como, o Estereótipo de Afetuosidade $(\alpha=.81)$.

Emoções associadas às pessoas idosas. Tendo como base o estudo de Fiske e colaboradores (2002), no presente estudo tivemos como base o questionário do programa imAGES (Marques et al., 2015), onde foi pedido aos participantes que pensassem nas pessoas com 65 anos ou mais, e dissessem o que sentem acerca delas: inveja, admiração, pena e desprezo. Para cada adjetivo as respostas foram medidas através de uma escala de Likert de 7 pontos (1- Discordo completamente a 7- Concordo completamente). Estes indicadores foram analisados de forma isolada.

Frequência de contacto com os avós. A frequência de contacto com os avós foi medida através de uma questão em que se pedia às crianças que pensassem no avô com quem estavam mais habitualmente e indicassem ao longo de um ano com que frequência costumavam estar com esse avô ("Pensa no avô/avó com quem te dás mais. Por ano com que frequência vês esse avô/avó?"). A resposta era dada numa escala que variava desde $1=$ menos de uma vez por ano até $6=$ todos os dias.

Tipo de contacto com os avós. Para além da frequência com os avós procurou-se ainda avaliar o tipo de contacto que as crianças estabeleciam com os seus avós. Estas questões foram inspiradas no estudo de Soliz e Harwood (2006) com estudantes universitários e adaptados para crianças nesta faixa etária. Neste sentido, as crianças eram questionadas relativamente aos seguintes aspetos do contacto com os seus avós: "Ajudas este(a) avô/avó nos seus recados e tarefas domésticas", "Quando eras mais novo(a), foste educado por este(a) avô/avó", "Discutes os teus problemas com este(a) avô/avó" e "Costumas receber conselhos deste(a) avô/avó." As respostas foram dadas numa escala de "Sim" ou "Não".

Qualidade percebida no contacto com os avós. A medida de perceção da qualidade do contacto com os avós foi adaptada de Marques et al., (2015) e de Harwood e colaboradores (2005) e foi medida através de quatro itens para avaliar a satisfação com o relacionamento: "a) Gosto muito deste(a) avô/avó", "b) Sou muito(a) amigo(a) deste(a) avô/avó", "c) É sempre muito divertido estar com este(a) avô/avó", "d) Estar com este(a) avô/avó pode ser um bocado aborrecido às vezes." Os itens de resposta foram medidos a partir de uma escala de Likert de 7 pontos (1- Discordo completamente a 7-Concordo completamente). A análise de consistência interna confirmou que estes itens alcançaram boas qualidades psicométricas $(\alpha=.86)$.

Foi ainda incluída uma questão aberta onde era pedido às crianças que indicassem a visão que tinham dos avós com quem passam mais tempo (i.e., "Diz-me, como vês esse avô/avó?”).

$\mathbf{O}$ avô/avó como parte da identidade familiar. A identidade familiar foi avaliada a partir de uma medida adaptada de Soliz e Harwood (2006). Foi pedido às crianças que respondessem às seguintes questões: a) Sinto-me orgulhoso por pertencer à mesma família que este(a) avô/avó; b) Este(a) avô/avó é uma parte importante na minha família; c) Os meus pais e este(a) avô/avó dão-se bem; d) No geral, os meus pais incentivam-me a ter uma relação com este(a) avô/avó; e) Os meus pais relembram-me para telefonar, escrever e/ou enviar email para este(a) avô/avó; f) Os meus pais dizem-me para ir com eles, quando vão visitar este(a) avô/avó. Os itens de resposta foram medidos numa escala de Likert de 7 pontos (1- Discordo completamente a 7- Concordo completamente). A análise de consistência interna confirmou que estes itens alcançaram uma confiabilidade aceitável $(\alpha=.61)$.

Saliência da idade do avõ/avó. Para medir a saliência da idade do avô/avó usou-se um item retirado do estudo de Soliz e Harwood (2006): “Até que ponto consideras este avô/avó como uma pessoa idosa típica?" ( 1 = De modo nenhum a 5 = Muito). 


\section{Procedimento}

Algumas das medidas utilizadas neste estudo foram adaptadas do estudo original de Soliz e Harwood (2006) com estudantes universitários. Neste sentido, foi efetuado o contacto com um dos autores do estudo, com o intuito de nos facultar a versão original do questionário aplicado no estudo. Posteriormente, as características originais em inglês foram submetidas a um processo de tradução para a língua portuguesa (por acordo de dois juízes independentes) e a linguagem foi adaptada à idade dos participantes. As restantes medidas utilizadas foram adaptadas do estudo com crianças anteriormente realizado por Marques et al. (2015). As medidas utilizadas no âmbito deste estudo faziam parte de um conjunto mais vasto de indicadores.

Após feitas as alterações, o instrumento foi pré-testado em cinco jovens, três do sexo feminino e dois do sexo masculino, com idades compreendidas entre os 11 e os 13 anos, com a autorização dos pais que foram devidamente informados acerca das características do estudo. No contacto inicial foi explicado aos jovens o objetivo do estudo. Com a realização do pré-teste pretendemos saber se o questionário era extenso ou não e se as questões eram de fácil compreensão, tendo, de uma maneira geral, todos eles dado um feedback positivo acerca do questionário. À posteriori, o questionário foi aplicado a jovens que integravam o Ensino Básico com 11, 12 e 13 anos, numa escola situada na Região do Algarve.

Os dados foram recolhidos através da distribuição dos questionários em formato de papel. Os questionários foram distribuídos em duas versões: Versão A - participantes que estabelecem contacto com os seus avós e Versão B - participantes que não estabelecem contacto com os seus avós ou já não têm avós vivos. Tendo em conta que o número que respondeu à versão B foi reduzida (2 participantes), não consideramos a análise desta versão.

Para a sua aplicação em contexto institucional foram obtidas as autorizações por parte da direção da Escola Básica. Adicionalmente, foram obtidos os consentimentos informados aos encarregados de educação dos alunos, conforme consta no Código Deontológico dos Psicólogos (Princípio Específico Consentimento Informado), neste contexto "entende-se por consentimento informado a escolha de participação voluntária do cliente, após ser-lhe dada a informação sobre a natureza e curso previsível desse

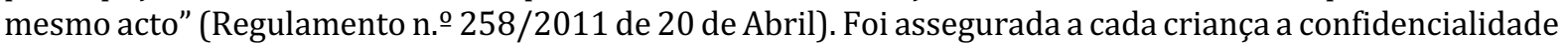
dos dados recolhidos e solicitada a concordância (através do pressuposto do consentimento informado) para participar na presente pesquisa.

\section{RESULTADOS}

\section{Estereótipos de envelhecimento: perceção de competência e afetuosidade}

A análise dos resultados permitiu replicar os resultados obtidos na literatura no sentido em que as crianças percebem as pessoas idosas como significativamente mais afetuosas $(M=6.17 ; S D=1.02)$ do que competentes $(M=5.51 ; S D=1.56), t(144)=-6.96, p<.001$.

\section{Emoções associadas às pessoas idosas}

Replicando também a literatura com adultos neste domínio (Fiske et al., 2002) verificam-se diferenças significativas nas emoções que as crianças associam às pessoas idosas, $F(3,432)=117.40, p<.001 ; \eta p^{2}=$ .45 , os resultados revelam que as pessoas idosas são percebidas sobretudo com admiração e pena. Seguemse a inveja e o desprezo. Todas estas diferenças são significativas entre si, $p<.05$ (Tabela 1).

Tabela 1. Emoções associadas às pessoas idosas

\begin{tabular}{lll}
\hline Tipo de emoção & $\boldsymbol{M}$ & $\boldsymbol{D P}$ \\
\hline Admiração & $5.28^{*}$ & 1.92 \\
Pena & $3.70^{*}$ & 2.26 \\
Inveja & $2.04^{*}$ & 1.76 \\
Desprezo & $1.74^{*}$ & 1.51 \\
\hline
\end{tabular}

Nota. $^{*} p<.05$

\section{Frequência e tipo de contacto com os avós}

A análise dos resultados revelou um grau elevado de contacto com os avós. De facto, a maioria das crianças inquiridas estão com os avós todos os dias (62.8\%) ou todas as semanas (26.2\%). Algumas crianças estão com os avós algumas vezes por ano (7.6\%), todos os meses (1.4\%) ou algumas vezes por ano (2.1\%). Nenhuma criança referiu estar apenas uma vez por ano com os avós.

Quando questionadas sobre o tipo de contacto que tinham com o seu avô/avó com quem estão mais frequentemente, as crianças referiram que costumavam receber conselhos deste avô/avó (89\%), ajudam 
este avô/avó nos seus recados e tarefas domésticas (84.8\%), discutem os seus problemas com o seu avô/avó (70.3\%). Cerca de metade da amostra inquirida referiu mesmo ter sido educado por este avô/avó quando era mais pequeno (54.5\%).

Qualidade percebida no contacto com os avós e avô como parte da identidade familiar

Quando inquiridos livremente acerca da opinião que tinham sobre o seu avô/avó de referência, a maioria dos participantes considera o seu/sua avô/avó: amigo(a) (68.2\%), simpático(a) (46.8\%), bom/boa (32.4\%) e disponível (31\%).

A resposta das crianças revela ainda que se sentem satisfeitas na sua relação com o avô/avó de referência $(M=4.18 ; D P=0.42), t(144)=119.30, p<.001$, e que percebem esse avô/avó como parte da identidade familiar $(M=4.58 ; D P=0.49 ; t(144)=112.88, p<.001)$.

\section{Saliência da idade do avô/avó}

Verifica-se que as crianças consideram o seu avô/avó como uma pessoa medianamente típica $(M=2.73$; $D P=1.45$ ). A amostra de participantes divide-se em relação a esta questão com $45.5 \%$ da amostra a considerar o seu avô/avó como pouco ou nada típico das pessoas idosas e $40 \%$ a considerarem como "mais ou menos típico" ou "típico" das pessoas idosas. Apenas 14.5\% dos participantes consideraram o avô/avó como "muito típico".

\section{Relação entre as variáveis}

Para testar as nossas hipóteses procurámos analisar a relação entre as variáveis do contacto com os avós com os estereótipos das emoções sentidas em relação às pessoas idosas de um modo geral. No caso do "tipo de contacto" considerámos apenas as categorias "discuto os problemas com o avô/avó" e "fui educado pelo avô/avó" por serem aquelas com variabilidade de resposta (Tabela 2).

Tabela 2. Correlações entre as variáveis relativas ao contacto com os avós e os estereótipos e emoções em relação às pessoas idosas

\begin{tabular}{|c|c|c|c|c|c|c|c|c|c|c|c|c|}
\hline & 1 & 2 & 3 & 4 & 5 & 6 & 7 & 8 & 9 & 10 & 11 & 12 \\
\hline $\begin{array}{l}\text { 1. Frequência de } \\
\text { contacto }\end{array}$ & -- & & & & & & & & & & & \\
\hline $\begin{array}{l}\text { 2. Discuto os } \\
\text { meus problemas } \\
\text { com o avô/avó }\end{array}$ & 0.10 & -- & & & & & & & & & & \\
\hline $\begin{array}{l}\text { 3. Fui educado } \\
\text { por esse avô/avó }\end{array}$ & 0.11 & $0.20 *$ & -- & & & & & & & & & \\
\hline $\begin{array}{lr}\text { 4. Avô } & \text { como } \\
\text { parte } & \text { da } \\
\text { identidade } & \\
\text { familiar } & \end{array}$ & $0.19^{*}$ & 0.12 & -0.07 & -- & & & & & & & & \\
\hline $\begin{array}{l}\text { 5. Saliência da } \\
\text { idade do avô/avó }\end{array}$ & $-0.21^{*}$ & -0.13 & -0.07 & -0.14 & -- & & & & & & & \\
\hline $\begin{array}{l}\text { 6. Qualidade do } \\
\text { contacto }\end{array}$ & 0.12 & -0.06 & -0.14 & 0.13 & -0.09 & -- & & & & & & \\
\hline $\begin{array}{l}\text { 7. Estereótipo de } \\
\text { Competência }\end{array}$ & -0.10 & 0.00 & $0.26^{* *}$ & -0.05 & 0.09 & -0.11 & -- & & & & & \\
\hline $\begin{array}{l}\text { 8. Estereótipo de } \\
\text { Afetuosidade }\end{array}$ & 0.11 & 0.05 & 0.04 & $0.15^{+}$ & 0.14 & -0.08 & $\begin{array}{l}0.68^{* *} \\
*\end{array}$ & -- & & & & \\
\hline 9. Inveja & $\overline{-}-25^{* *}$ & -0.08 & -0.03 & 0.09 & $0.19 *$ & 0.03 & $0.19 *$ & 0.06 & -- & & & \\
\hline 10. Admiração & 0.05 & $0.16^{+}$ & $0.21^{*}$ & 0.00 & 0.02 & -0.13 & $0.39^{* *}$ & $\begin{array}{l}0.31^{* *} \\
*\end{array}$ & 0.13 & -- & & \\
\hline 11. Pena & 0.05 & -0.13 & -0.07 & -0.09 & 0.09 & 0.13 & $\overline{-}-22^{* *}$ & -0.13 & 0.10 & -0.10 & -- & \\
\hline 12. Desprezo & $\begin{array}{l}- \\
0.35^{* *} \\
*\end{array}$ & $-\overline{0.19 *}$ & -0.10 & -0.11 & 0.04 & 0.06 & 0.02 & - $0.17 *$ & $0.25^{*}$ & $\begin{array}{l}0.31^{* *} \\
*\end{array}$ & $\begin{array}{l}0.35^{* *} \\
*\end{array}$ & -- \\
\hline$M$ & 5.46 & - & - & 4.58 & 2.73 & 4.18 & 5.51 & 6.17 & 2.04 & 5.98 & 3.70 & 1.74 \\
\hline$D P$ & 0.86 & - & - & 0.49 & 1.45 & 0.42 & 1.56 & 1.02 & 1.76 & 1.92 & 2.26 & 1.51 \\
\hline
\end{tabular}

Nota. ${ }^{*} p<.05 ;{ }^{* *} p<.01 ;{ }^{* * *} p<.001 ;{ }^{+} p<.07$ 
De interesse para o teste das nossas hipóteses verifica-se que são as crianças que revelam ter maior frequência de contacto com os avós aquelas que revelam também considerar o avô como parte da identidade familiar e sentem por ele menos inveja e menos desprezo. No mesmo sentido, parece ser sobretudo o facto de terem sido educadas pelo avô/avó o fator que faz a diferença no modo como as crianças percebem as pessoas idosas de um modo geral. Neste sentido, os resultados revelam uma correlação significativa e positiva entre o facto de terem sido educadas pelo avô/avó e perceberem as pessoas idosas como mais competentes e mais admiráveis. 0 facto de discutirem problemas com o avô/avó está significativamente correlacionado com o sentimento de maior admiração (embora apenas a nível marginal neste caso) e de menor desprezo pelas pessoas idosas de um modo geral. Ainda, o facto de considerarem o avô/avó como fazendo parte da identidade familiar está marginalmente correlacionado com perceberem esse avô/avó como mais afetuoso (embora em níveis apenas marginais de significância).

Para analisar o efeito da criança ter sido educada pelo avô/avó no estereótipo ambivalente das pessoas idosas como "simpáticas, mas incompetentes", realizámos uma ANOVA mista com "ser educado pelo avô/avó" como fator inter-participantes e a avaliação das pessoas idosas como competentes ou afetuosas como fator intra-participantes. Os resultados revelaram um efeito de interação significativo entre o fator "ser educado pelo avô/avó" e a avaliação de competência e afetuosidade dos idosos de um modo geral, $F(1$, $143)=15.19, p<.001, \eta p^{2}=.10$. Este efeito de interação significa que quando as crianças não foram educadas pelos avós defendem mais o estereótipo "simpáticas mas incompetentes" do que quando as crianças foram educadas pelos avós (Figura 1).

\section{口Competência $\square$ Afectuosidade}

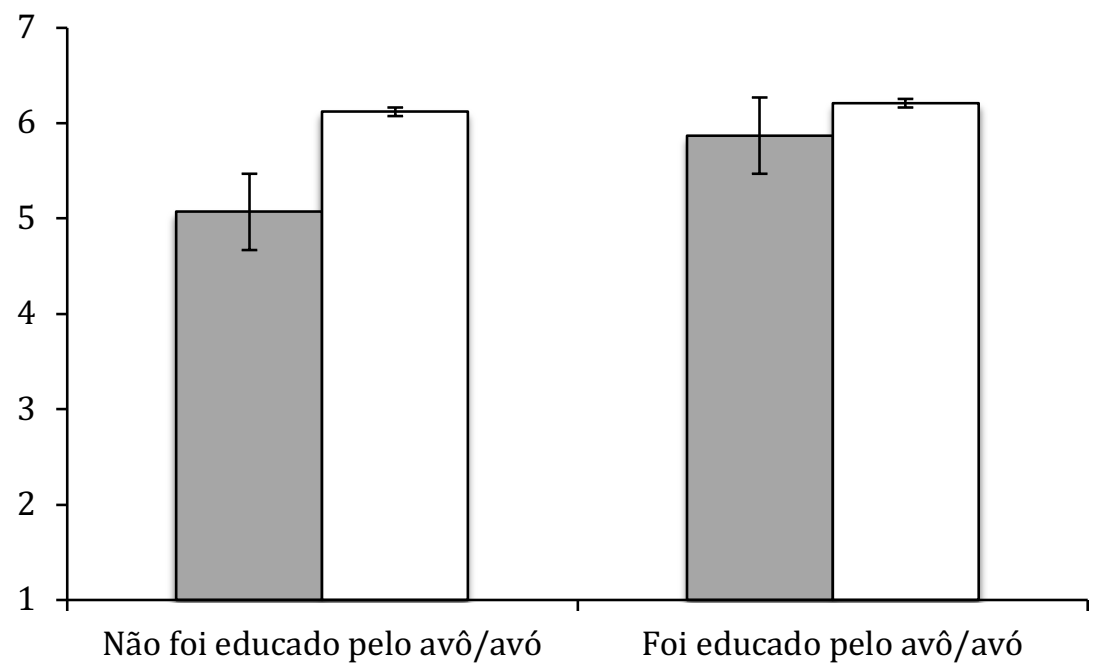

Figura 1. Avaliação da competência e afetuosidade das pessoas idosas em geral em função da criança ter sido ou não educada pelo avô/avó

Para testar a hipótese de que a saliência da idade do avô/avó como moderador dos efeitos da identidade familiar nos estereótipos e emoções associados às pessoas idosas, seguimos as instruções propostas por Aiken et al., (1991). Sendo assim, utilizámos um modelo de regressão linear onde usámos como preditores a identidade familiar, a saliência da idade e o produto destas duas variáveis para explicar cada uma das várias variáveis dependentes relativas ao estereótipo e emoções associadas às pessoas idosas: o estereótipo de competência, o estereótipo de afetuosidade e cada uma das quatro emoções avaliadas em relação às pessoas idosas. As variáveis preditoras foram centradas. A análise destes resultados permitiu verificar que não existiam efeitos significativos de moderação da saliência da idade no efeito da identidade familiar em nenhuma das VDs em análise. A única exceção foi no caso da emoção "Admiração" onde se obteve um efeito de interação marginalmente significativo, $\beta=-0.16, S E=0.25, t(141)$ $=-1.86, p=.065$ (ver Tabela 3). De modo a compreender melhor este efeito, realizámos uma análise pormenorizada das retas da regressão em função da condição de saliência da idade (baixa ou elevada). Estes resultados revelaram que apesar da moderação ser marginalmente significativa, nenhum dos perfis analisados atinge significância estatística, $p>$.10. De qualquer modo, o padrão encontrado é contrário à H3 formulada já que, no caso em que os participantes reportam uma identidade familiar elevada, as outras 
pessoas idosas são vistas com maior admiração quando os próprios avós são percebidos como menos típicos das pessoas idosas.

Tabela 3. Efeitos da identidade familiar e saliência da idade do avô/avó na admiração pelas pessoas idosas de um modo geral

\begin{tabular}{lccc}
\hline Variáveis & b & SE & $\boldsymbol{\beta}$ \\
\hline Identidade familiar & 0.16 & 0.34 & 0.04 \\
Saliência da idade & 0.06 & 0.11 & 0.04 \\
Identidade familiar x Saliência da idade & -0.46 & 0.25 & $-0.16^{+}$ \\
\hline
\end{tabular}

Nota. A identidade familiar e a saliência da idade foram centradas de acordo com a sua média; ${ }^{+} \mathrm{p}<.07$

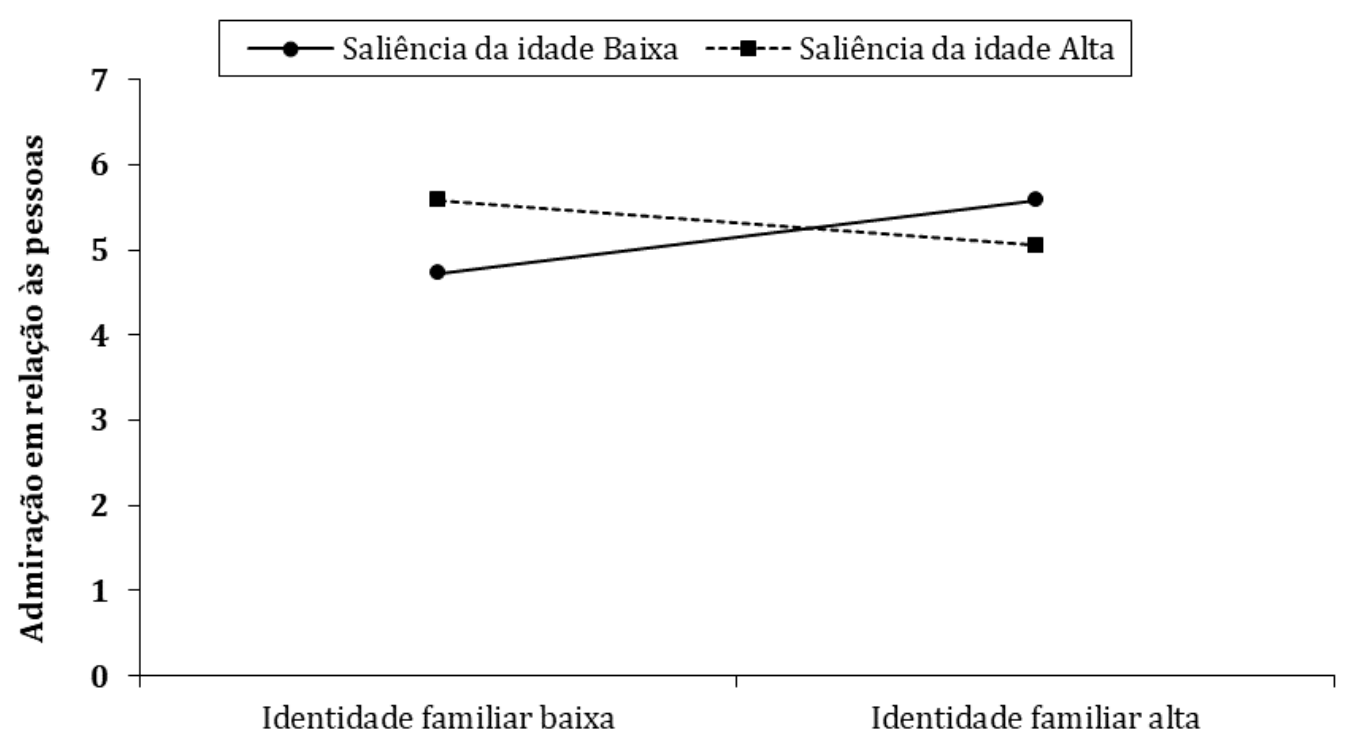

Identidade familiar

Figura 2. Análise do efeito de moderação da saliência da idade no efeito da identidade familiar na admiração sentida face às pessoas idosas de um modo geral

\section{DISCUSSÃo}

Este estudo teve como objetivo analisar o papel do contacto com os avós nas perceções idadistas das crianças com idades entre os 11-13 anos em relação às pessoas idosas. Especificamente, quisemos compreender de que modo a frequência e a qualidade de contacto com os avós se associavam à diminuição do estereótipo paternalista das pessoas idosas como "simpáticas, mas incompetentes". Neste sentido, e replicando as hipóteses da literatura neste domínio com estudantes universitários, os resultados obtidos mostram que estas variáveis se associam positivamente à perceção das pessoas idosas como competentes e na expressão de admiração face a estas. Assim, e confirmando as hipóteses 1 e 2, os resultados são consistentes com aqueles que têm sido encontrados noutros países e grupos etários (Kite \& Johnson, 1988; Soliz \& Harwood, 2006). Replicando os resultados obtidos por Flamion e colegas (2017) no contexto belga, mostramos, também, que é sobretudo a dimensão da qualidade do contacto com os avós aquela com maior relevância na diminuição dos níveis de idadismo face aos mais velhos. Em particular, e de forma inovadora, destacamos o papel relevante que a educação pelos avós tem neste processo. De facto, são as crianças que afirmam ter sido educadas pelos seus avós aquelas que têm uma visão menos paternalista das outras pessoas idosas. Se considerarmos o paternalismo como uma forma indirecta de preconceito em relação às pessoas idosas (França \& Monteiro, 2013; Monteiro, 2002), é possível verificar que o contacto mais duradouro com os avós tem uma influência importante neste tipo de representação nas crianças.

No contexto deste trabalho procurou-se, ainda, explorar o papel que a perceção do avô/avó como parte da identidade familiar, e a forma como esse avô/avó era percebido como um elemento típico das categorias das pessoas idosas, afetava o idadismo em relação às outras pessoas idosas. No entanto, no presente estudo não foi possível replicar os resultados obtidos com estudantes universitários por Soliz e Harwood (2006), já que apenas se verificou uma interação marginalmente significativa e no sentido contrário ao esperado. De facto, o padrão encontrado, apesar de não atingir resultados significativos, 
mostrava que as crianças admiravam mais as pessoas idosas quando percebiam o seu avô/avó como fazendo parte da sua identidade familiar, mas sendo pouco típico das pessoas idosas. Este resultado é interessante e deveria ser alvo de maior exploração em estudos futuros. Especificamente, é possível que as crianças não percebam o seu avô como uma pessoa idosa típica, mas ainda assim a conceptualizem como pertencendo à categoria das pessoas idosas. De facto, existem alguns estudos que mostram que é justamente a apresentação de exemplares medianamente atípicos da categoria que encerra um potential significativo de mudança dos estereótipos (Garcia-Marques \& Mackie, 1999; Marques et al., 2015). Sendo assim, ao perceberem o seu avô/avó com quem estabelecem uma relação de laços profundos e positivos como uma pessoa idosa menos incompetente, terão uma tendência a generalizar esse efeito para as outras pessoas idosas no geral que lhes são desconhecidas.

Apesar de interessantes, estes resultados carecem de uma maior exploração no futuro. Por exemplo, não é muito claro porque razão é a perceção de terem sido educadas pelos avós a variável que maior destaque assume na diminuição do idadismo. Apesar de constituir de forma clara uma variável que operacionaliza uma maior frequência e, possivelmente, qualidade de contacto, seria importante compreender que aspetos desta "educação" são de facto relevantes (para uma revisão da teoria do contacto ver Monteiro, 2017). Neste sentido, também seria importante compreender quais os limites de tempo passado com os avós que são necessários para surtir efeitos ou se as mudanças são mais expectáveis não em função do tempo passado, mas da qualidade dos encontros entre os avós e os netos. Do mesmo modo, seria muito importante no futuro explorar melhor a interação marginal que surgiu entre a identidade familiar e a saliência da idade do avô/avó. Se a diminuição do idadismo ocorre sobretudo quando os avós são percebidos como menos típicos, então talvez fosse importante compreender qual a representação específica dos avós e das outras pessoas idosas que estas crianças partilham e quais as características centrais que estes avós possuem que propiciam esta mudança nas representações.

Os resultados obtidos neste estudo são muito relevantes e apresentam um potencial elevado para o desenho de programas de intervenção no domínio da diminuição do idadismo em crianças (Marques et al., 2015). A aposta nas relações intra-familiares entre avós e netos pode ser uma via crucial para combater as relações de conflito intergeracional que se podem estabelecer fora do contexto familiar. Face a uma forte pressão do envelhecimento demográfico, com consequências muito relevantes, por exemplo ao nível da sustentabilidade do sistema público de pensões e dos gastos inerentes ao envelhecimento das populações (e.g., saúde), é expectável que possam surgir situações em que é relativamente fácil instigar o conflito entre as gerações apelando a motivos de justiça intergeracional. Nestes contextos, as cisões entre as gerações poderão advir principalmente se não se tiver em atenção uma divisão equitativa dos encargos para as diferentes gerações. No entanto, este tipo de conflitos deverá ser evitado na defesa de uma sociedade coesa e para todas as idades. É neste sentido que os resultados sobre a positividade e benefícios das relações entre avós e netos assume uma importância crucial. Consideramos que este caminho é promissor para a construção de uma sociedade harmoniosa em que todos possam viver com dignidade num contexto de novos e desafiantes equilíbrios.

\section{REFERÊNCIAS}

Aiken, L. S., West, S. G., \& Reno, R. R. (1991). Multiple regression: Testing and interpreting interactions. Sage. Allport, G. W. (1954). The nature of prejudice. Addison-Wesley.

Brown, C. S., \& Bigler, R. S. (2004). Children's perceptions of gender discrimination. Developmental Psychology, 40(5), 714-726. https://doi.org/10.1037/0012-1649.40.5.714

Brown, R., \& Hewstone, M. (2005). An Integrative Theory of Intergroup Contact. In M. P. Zanna (Ed.), Advances in experimental social psychology, (Vol. 37, pp. 255-343). Elsevier Academic Press. https://doi.org/10.1016/S0065-2601(05)37005-5

Caspi, A. (1984). Contact hypothesis and inter-age attitudes: A field study of cross-age contact. Social Psychology Quarterly, 4(1), 74-80. https://doi.org/10.2307/3033890

Crawford, P. A., \& Bhattacharya, S. (2014). Grand images: Exploring images of grandparents in picture books. Journal of Research in Childhood Education, 28(1), 128-144. https://doi.org/10.1080/02568543.2013.853004

Cuddy, A. J. C., Norton, M. I., \& Fiske, S. T. (2005). This old stereotype: The pervasiveness and persistence of the elderly stereotype. Journal of Social Issues, 61(2), 267-285. https://doi.org/10.1111/j.15404560.2005.00405.x.

Dias, C. \& Silva, D. (1999). Os avós: uma revisão da literatura nas três últimas décadas. In T. Feres-Carneiro (Org.). Casal e família, entre a tradição $e$ a transformação. Nau. https://doi.org/10.1590/0102.3772e324214 
Drew, L., \& Silverstein, M. (2007). Grandparents' psychological well-being after loss of contact with their grandchildren. Journal of Family Psychology, 21(3), 372-379. https://doi.org/10.1037/08933200.21.3.372

Dunifon, R. \& Bajracharya, A. (2012). The Role of Grandparents in the Lives of Youth. Journal of Family Issues, 33(9), 1168-1194. https://doi.org/10.1177/0192513X12444271

Dutra, H. (2008). O papel da avó na promoção de estilos de vida saudáveis junto dos netos [Dissertação de Mestrado não publicada]. Faculdade de Medicina da Universidade de Lisboa.

Fiske, S. T., Cuddy, A. J. C., Glick, P. S., \& Xu, J. (2002). A model of (often mixed) stereotype content: Competence and warmth respectively follow from perceived status and competition. Journal of Personality and Social Psychology, 82, 878-902. https://doi.org/10.1037/0022-3514.82.6.878

Flamion, A., Missotten, P., Marquet, M., \& Adam, S. (2017). Impact of Contact with Grandparents on Children's and Adolescents' Views on the Elderly. Child development, 90(4), 1155-1169. https://doi.org/10.1111/cdev.12992

França, D. X., \& Monteiro, M. B. (2013). Social norms and the expression of prejudice: The development of aversive racism in childhood. European Journal of Social Psychology, 43(4), 263-271. http://doi.org/10.1002/ejsp.1965

França, L., Silva, A., \& Barreto, M. (2010). Programas intergeracionais: Quão relevantes podem ser para a sociedade brasileira. Revista Brasileira de Geriatria e Gerontologia, 13(3), 519-531.

Garcia-Marques, L., \& Mackie, D. M. (1999). The impact of stereotype-incongruent information on perceived group variability and stereotype change. Journal of Personality and social Psychology, 77(5), 979. https://psycnet.apa.org/buy/1999-01257-006

Glaser, K., Price, D., Montserrat, E. R., Gessa, G., \& Tinker, A. (2013). A prestação de cuidados pelos avós na Europa: as políticas familiares e o papel dos avós na prestação de cuidados infantis. Grandparent Plus. Fundação Calouste Gulbenkian.

Greenberg, J., Schimel, J., \& Mertens, A. (2004) Ageism: Denying the face of the future. In T. D. Nelson (Ed.), Ageism: Stereotyping and prejudice against older persons (pp. 27-48). MIT Press.

Hagestad, G. O., \& Uhlenberg, P. (2005). The social separation of old and young: A root of ageism. Journal of Social Issues, 61(2), 343-360. https://doi.org/10.1111/j.1540-4560.2005.00409.x

Harwood, J., Hewstone, M., Paolini, S., \& Voci, A. (2004). Intergroup contact theory, the grandparentgrandchild relationship, and attitudes towards older adults. Unpublished manuscript.

Harwood, J., Hewstone, M., Paolini, S., \& Voci, A. (2005). Grandparent-grandchild contact and attitudes toward older adults: Moderator and mediator effects. Personality and Social Psychology Bulletin, 31(3), 393-406. https://doi.org/10.1177/0146167204271577

Hewstone, M., \& Brown, R. (1986). Contact is not enough: An intergroup perspective on the 'contact hypothesis. In M. Hewstone \& R. Brown (Eds.), Social psychology and society. Contact and conflict in intergroup encounters (pp. 1-44). Basil Blackwell.

INE (2002). O envelhecimento em Portugal. Serviço de Estudos para a População do Departamento de Estatísticas Censitárias e de População.

Jarrott, S. (2011). Where have we been and where are we going? Content analysis of evaluation research of intergenerational programs. Journal of Intergenerational Relationships, 9(1), 37-52. https://doi.org/10.1080/15350770.2011.544594

Johnson, R. C., \& Medinnus, G. R. (1974). Child psychology: Behavior and development (3a ed.). John Wiley \& Sons, Inc. https://doi.org/10.1002/1098-2337(1985)11:1<27::AID-AB2480110105>3.0.CO;2-0

Kaplan, M., \& Larkin, E. (2004). Launching intergenerational programs in early childhood settings: A comparison of explicit intervention with an emergent approach. Early Childhood Education Journal, 31(3), 157-163. https://doi.org/10.1023/B:ECEJ.0000012133.71718.2b

Kemp, T. S. (2005). The origin and evolution of mammals. University Press.

Killen, M. \& Rutland, A. (2011). Children and social exclusion: morality, prejudice and group identity. WileyBlackwell.

Kite, M. E., \& Johnson, B. T. (1988). Attitudes toward older and younger adults: A meta-analysis. Psychology and Aging, 3(3), 233-244. https://doi.org/10.1037//0882-7974.3.3.233

Marques, S. (2011). Discriminação da terceira idade. Coleção de Ensaios da Fundação Francisco Manuel dos Santos. Relógio D'Água Editores.

Marques, S., Ramos, M. R., Cruz, J., Dias, M. S., Eloy, S., Carreiro, M., \& Vilar, E. (2015). Matter Over Mind: Environmental Influences on the Activation of Aging Stereotypes. The Gerontologist, 55, 504-504. https://doi.org/10.1093/geront/gnv222.02

Marques, S., Vauclair, C.M., Rodrigues, R., Mendonça, J., Gerardo, F., Cunha, F., Sena,C., \& Leitão, E. (2015). imAGES: Intervention program to prevent ageism in children. Santa Casa da Misericórdia de Lisboa \& LEYA. 
Mendonca, J., Marques, S., \& Abrams, D. (2018). Children's attitudes regarding older people: current and future directions. In L. Ayalon \& Claus Tesch-Roemer (Ed.), Contemporary perspectives on ageism (pp. 517-548). Springer Nature.

Monteiro, M. B. (2002). A construção da exclusão social nas relações interétnicas: Orientações teóricas e de investigação na perspectiva do desenvolvimento. Psicologia, 16(2), 271-292. https://doi.org/10.17575/rpsicol.v16i2.481

Monteiro, M. B., França, D. X., \& Rodrigues, R. (2009). The development of intergroup bias in childhood: How social norms can shape children's racial behaviours. International Journal of Psychology, 44(1), 29-39. https://doi.org/10.1080/00207590802057910

Monteiro, M.B. (2017). Relações intergrupais. In J. Vala e M.B. Monteiro (Eds). Psicologia Social (10ae ed, pp. 493-568). Fundação Calouste Gulbenkian.

Montepare, B., Kwong See, S. T. \& Heller, R. B. (2005). Measuring ageism in children. In E. B. Palmore, L. Branch \& D. K. Harris (Eds.), Encyclopedia of ageism (pp. 210-216). The Haworth Press, Inc.

Nelson, D. (Ed.), Ageism: Stereotyping and prejudice against older persons (pp. 77-125). MIT Press.

Newman, S., Faux, R., \& Larimer, B. (1997). Children's views on aging: Their attitudes and values. The Gerontologist, 37(3), 412-417. https://doi.org/10.1093/geront/37.3.412

Pettigrew, T. F., \& Tropp, L. R. (2000). Does intergroup contact reduce prejudice? Recent meta-analytic findings. In S. Oskamp (Ed.), Reducing prejudice and discrimination: The Claremont symposium (pp. 93-114). Erlbaum.

Pires, M. (2010). Presença e papel dos avós: estudo de caso [Dissertação de Mestrado não publicada]. Departamento de Educação da Universidade de Aveiro.

Rodrigues, R. B., Monteiro, M. B., \& Rutland, A. (2012). O que pensam e dizem crianças portuguesas "Brancas" sobre grupos "raciais"? O papel de duas normas grupais conflituantes na expressão e inibição do preconceito na infância. In J. H. António \& V. Policarpo (Eds.), Os imigrantes e a imigração aos olhos dos Portugueses: Manifestações de preconceito e perspectivas sobre a inserção de imigrantes (pp. 185-220). Fundação Calouste Gulbenkian.

Seefeldt, C., Jantz, R. K., Galper, A., \& Serock, K. (1977). Using pictures to explore children's attitudes toward the elderly. The Gerontologist, 17(6), 506-512. https://doi.org/10.1093/geront/17.6.506

Silverstein, M., \& Parrott, T. M. (1997). Attitudes toward public support of the elderly: Does early involvement with grandparents moderate generational tensions?. Research on Aging, 19(1), 108132. https://doi.org/10.1093/geront/17.6.506

Soliz, J. \& Harwood, J. (2003). Perceptions of communication in a family relationship and the reduction of intergroup prejudice. Journal of Applied Communication Research, 31(4), 320-345. https://doi.org/10.1080/1369681032000132582

Soliz, J., \& Harwood, J. (2006). Shared family identity, age salience, and intergroup contact: Investigation of the grandparent-grandchild relationship. Communication Monographs, 73(1), 87-107. https://doi.org/10.1080/03637750500534388

Steele, J., Choi, Y. S., \& Ambady, N. (2004). Stereotyping, prejudice and discrimination. In T. A. Thorkildsen \& H. J. Walberg (Eds.), Nurturing morality (pp. 77-97). Springer. https://doi.org/10.1007/978-14757-4163-6_5

Vauclair, C. M., Borges Rodrigues, R., Marques, S., Esteves, C. S., Cunha, F., \& Gerardo, F. (2017). Doddering but dear... even in the eyes of young children? Age stereotyping and prejudice in childhood and adolescence. International Journal of Psychology, 53, 63-70. https://doi.org/10.1002/ijop.12430

Veleda, A., Vaz, M., Soares, M., Baich, A. \& Santos, S. (2006). Os significados e contribuições da convivência entre avós e netos para o desenvolvimento da criança. Psychologica, 43, 27-40.

\begin{tabular}{ll}
\multicolumn{2}{c}{ Historial do artigo } \\
Recebido & $04 / 2018$ \\
Aceite & $07 / 2020$ \\
Publicado & $12 / 2020$
\end{tabular}

